\title{
The Effect of Simulation-Based Training About Emergencies in and Approaches to Delivery Given to Emergency Personnel
}

\author{
Zumrut Yilar Erkek ${ }^{1}$ (D) Ozgur Alparslan ${ }^{1}$ (D) , Serap Ozturk Altinayak ${ }^{2}$ (D) \\ ${ }^{1}$ Tokat Gaziosmanpasa University Faculty of Health Science, Department of Midwifery, Tokat, Turkey. \\ ${ }^{2}$ Ondokuz Mayis University Faculty of Health Science, Department of Midwifery, Samsun, Turkey.
}

Correspondence Author: Zumrut Yilar Erkek

E-mail: zyilar@hotmail.com

Received: $17.07 .2020 \quad$ Accepted: 22.01.2021

\begin{abstract}
Objective: This study was carried out to determine the effect of the medium level simulation-based training about "Emergencies in and Approaches to Delivery" given to the personnel working in emergency health services on the change in their current knowledge about emergency interventions in delivery.

Methods: The study used a quasi-experimental design. It was carried out with 232 personnel working in emergency health services. Data were collected using "Information Form" and "Knowledge Test for Emergencies in Delivery (ED)". The study included the teaching of the relevant topics to the participants, administration of the knowledge test, the application of the subjects taught using a simulator in the laboratory.

Results: Of the emergency health service personnel participating in the study, $68.5 \%$ were found to not have adequate knowledge for emergencies in delivery. As a result of the training given, the mean of the total pretest score obtained from the ED was $37.17 \pm 10.36$, and the mean of the total posttest score was $70.14 \pm 11.33$, and the post-training difference was found to be statistically significant.

Conclusion: According to the findings, it can be said that the training given to the emergency health service personnel increased their knowledge about emergencies in and approaches to delivery significantly and that the education was effective.

Keywords: Delivery, emergencies during delivery, emergency health service personnel, midwifery, simulation training, management of delivery emergencies.
\end{abstract}

\section{INTRODUCTION}

Emergency healthcare is one of the important components of primary healthcare services, which is defined as a discipline that includes rapid intervention and decisionmaking necessary to prevent further harm or death of patients by providing emergency care from the reporting of an injury or disease to the provision of definitive treatment (1-3). Another of these components is emergency obstetric care services (EMOC). EMOC describes the services provided in cases that occur in the 42-day period during pregnancy, birth and postpartum, threatening the life of the mother and baby and requiring emergency intervention. These services are extremely effective in reducing maternal and neonatal mortality rate, which is the most important indicator of development level of a country in worldwide (1).

Nearly half of child deaths and about one-third of maternal deaths occurring from the year 2000 to the present day have decreased. It is getting more difficult to reach better values than this level. Many factors such as economic conditions (e.g. lack of financial opportunities for transportation or health care), cultural aspects (e.g. lack of value for woman's life), and geographic conditions (e.g. distance from health institution, the inappropriateness of roads) prevent women from accessing healthcare services, which results in the current situation. Regardless of the conditions, any delay in a woman's access to any service can, unfortunately, cost her life (4-8). According to the results of the National Maternal Mortality Study conducted to determine the rate and cause of maternal deaths in Turkey (NMMS), $10.4 \%$ of maternal deaths occur on the road during the transfer or referral of women to a health institution (9). For this reason, personnel working in emergency health services equipped to provide EMOC can prevent most maternal deaths. To accomplish this, health institutions should provide health personnel with the highest level of knowledge and skills related to the services to be provided in emergencies that may occur frequently in obstetrics, as well as replenishing the deficiencies of medical equipment and infrastructure. It should be remembered that first aid services that stabilize the health status of women before being referred are life-saving $(10,11)$. 
Prolonged delivery, cord prolapse, shoulder dystocia, placental anomalies, hemorrhage, preeclampsia-eclampsia, HELLP syndrome, position and presentation anomalies, premature rupture of membranes, and premature birth threat are among common obstetric complications (12). Shoulder dystocia development in $0.54 \%$ of vaginal deliveries was reported by Sukgen et al. (2020); in the study of Ingeç et al. (2005) the rate of eclampsia in pregnant women was found as $1.2 \%$, Queenan et al. (2012) demonstrated approximately $1-2 \%$ of all births have placental retention; and Su et al. (2012) reported that uterine atony encountered in every twenty births. Each of these complications are important problems that threaten the life of the mother and baby. Determining the possible condition without delay and administering the appropriate intervention will be life-saving.

Administration of the quickest and appropriate intervention by healthcare personnel or the prompt referral of the patient in line with procedures in cases where necessary makes it possible to prevent maternal mortality and morbidity in an emergency obstetric case. The first condition for quick decision-making requires an awareness of the complications, signs, and symptoms that may occur during pregnancy, delivery, and the postpartum period, and also the knowledge of how to administer appropriate interventions in the correct sequence and in an appropriate way $(9,19-22)$.

The role of health personnel is very important in the provision of emergency health services. Ambulance services, which are important members of this team, have the same significance (23). The medical personnel serving in the ambulance are not midwives; they are often paramedics or emergency medical technicians (EMT). Therefore, these professionals are expected to have the current medical knowledge and skills necessary for issues related to emergencies during delivery. Otherwise, mothers and babies may experience health problems or even lose their life related to the delivery process (3). In this context, the present study is thought to be highly significant in terms of providing midwives, nurses, health officers, EMT, paramedics, and physicians working in the stations of Health Services in Emergencies and Disasters Department of Health Directorate with up-to-date and evidence-based information and skills to meet the needs of women with pregnancy during delivery and emergencies. There are research results in the literature that support this. Walker et al. (2014) determined that there was an increase in team performance and self-efficacy levels of midwives and obstetricians who participated in simulation-based training. Calvert et al. (2013) found that the team participating in the simulation training was more successful in intervening in the eclampsia crisis. Draycott et al. (2000) determined that the rate of injuries in the baby due to shoulder dystocia decreased from $9.3 \%$ to $2.3 \%$ after simulation-based training. Besides, Merien et al. (2010) found that midwives and obstetricians who completed the simulation training carried out the delivery within 5 minutes in cases of shoulder dystocia delivery. Dayal et al. (2009) performed a study with medical students and reported that in the experimental group in which the simulation method was applied, the performance of the students in vaginal birth maneuvers, their participation in clinical applications and their self-confidence were higher than the control group.

The present study was conducted to evaluate the effect of training about 'Emergencies and Approaches during Delivery' given to all personnel working in the stations of Health Services in Emergencies and Disasters Department in a province in the Central Black Sea Region on the changes in their current knowledge related to emergencies during delivery.

The study's hypotheses are:

HO: Simulation-based training given to emergency personnel about emergencies and approaches in delivery has no effect on their knowledge level.

$\mathrm{H} 1$ : Simulation-based training given to emergency personnel about emergencies and approaches in delivery has effect on their knowledge level.

\section{METHODS}

\subsection{Study Type}

The study used a pretest-posttest, non-control group, quasiexperimental design.

\subsection{Sample}

The study consisted of 295 personnel (EMT, paramedics, physicians, health officers, nurses, and midwives) working in the stations of Health Services in Emergencies and Disasters Department in a province in the Central Black Sea Region between (01 March 2017 and 31 December 2017). The study was carried out with 232 participants due to the personnel on leave, moving to another institution, on breastfeeding leave, or assignment to a different post.

\subsection{Data Collection Tools}

A 13-item "Information Form" for the evaluation of the training and a "Knowledge Test for Emergencies in Delivery (ED)" with 25 multiple-choice items for emergencies in and approaches to labor were used.

\subsection{The Information Form}

The form designed by the training coordinators consisted of 13 items aiming to collect data about socio-demographic characteristics, education status, and professional status of the participants, and their views about delivery. This form was administered to the participants only once before the training. 


\subsection{ED Knowledge Test}

This form, which aimed to measure the level of knowledge of the staff receiving the training, was developed by the researchers based on a literature review $(9,29-32)$.

The knowledge test consisted of items including delivery and risky situations that can be encountered most frequently during delivery. The distribution of the items by topics was normal delivery (6 questions), umbilical cord anomalies (4 questions), placental anomalies (4 questions), shoulder dystocia (4 questions), breech delivery (3 questions), preeclampsia-eclampsia (2 questions), amniotic fluid anomalies (1 question), and postpartum hemorrhage (1 question). The test was made up of 25 multiple choice questions, each of which had 5 options. Each question had only one correct option and was evaluated over 4 points. The minimum and maximum scores that could be obtained from the knowledge test ranged between 0 and 100 points.

For the content validity of the knowledge test questions, the test was submitted to the opinions of 5 experts who had already been studying in the field of risky delivery management and simulation education. Lawshe technique was utilized to evaluate the content validity of the items in the test. According to the Lawshe technique, the minimum fit criterion for five experts was evaluated as 0.99 (33). No items with a content validity ratio below 0.99 were detected in the test. To test the comprehensibility of the questions, the test was piloted to 10 personnel who did not know about the content of the test, and the test was finalized.

The pretest application was carried out after the first meeting with the participants, just before the training. Posttests were administered after the completion of the training. The tests were evaluated immediately after the 45-minute response time given for the tests. After evaluating the tests, the participants were given the correct answers, and necessary explanations about the questions were made.

\subsection{Applied Training for Emergencies and Approaches during Delivery}

The training was given in the applied training room and birth simulator application laboratories of the Health Sciences Faculty of a University in the Central Black Sea Region. The training sessions were given once or twice a month, in a total of 8 hours on a working day by two faculty members who worked in the Midwifery Department of the Faculty of Health Sciences and who were experts in the field. The pretest and posttest administration times of the information form were not included in the total training time. In the training held with 12 groups in total, the group sizes ranged between 16 and 25 people.

The training topics included emergencies that might be encountered during delivery such as normal delivery, breech delivery, placental anomalies, shoulder dystocia, umbilical cord prolapse, preeclampsia-eclampsia, and the management of hemorrhage. The topics were first taught in the classroom environment using teaching methods and materials such as lecturing, slide shows, videos, questionanswer, and demonstrations ( 4 hours theoretically). Then, a 4-hour long session was performed on a birth simulator in the laboratory (Figure 1). The applications were first carried out by the trainers on a low-fidelity simulator in the delivery laboratory. Then each participant performed each application at least once under the supervision of the trainers.

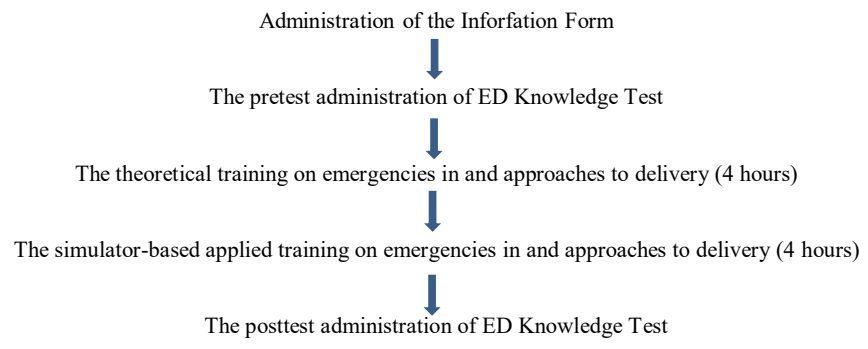

Figure 1. Flow diagram of the study

\begin{tabular}{|c|c|c|}
\hline TOPIC & PRESENTATION FORMAT & HOUR \\
\hline Normal delivery & \multirow{6}{*}{$\begin{array}{l}\text { Slide shows, videos, question- } \\
\text { answer, and demonstrations }\end{array}$} & 08:00-08:30 \\
\hline Breech delivery & & $08: 45-09: 15$ \\
\hline Shoulder dystocia & & 09:30-10:00 \\
\hline Placental anomalies, umbilical cord prolapse & & $10: 15-10: 45$ \\
\hline Preeclampsia-eclampsia & & 11:00-11:30 \\
\hline Management of hemorrhage & & $11: 45-12: 15$ \\
\hline Normal delivery practice & \multirow{5}{*}{$\begin{array}{l}\text { Simulation training (Delivery } \\
\text { simulator) }\end{array}$} & $13: 15-13: 45$ \\
\hline Breech delivery practice & & 14:00-14:30 \\
\hline Application of shoulder dystocia maneuvers & & $14: 45-15: 15$ \\
\hline Cord prolapse flow chart application & & $15: 30-16: 00$ \\
\hline Bleeding management flow chart application & & $16: 15-16: 45$ \\
\hline
\end{tabular}

Figure 2. Group training content

\subsection{Ethics of the Study}

In the study, necessary permissions were taken for the personnel (EMT, paramedic, physician, health officer, nurse, and midwife) working in the Emergency and Disasters Health Services of the Health Directorate for the day when the study would be carried out from the Public Health Directorate of the province where the study was conducted.

Ethical approval was obtained before starting the study. The written institutional permission was obtained from the Faculty of Health Sciences of the university where the study was conducted. Informed consent of the participants who agreed to participate in the study was obtained. Ethical approval of Cumhuriyet University Non-Interventional Clinical Research Ethics Committee (Decision no: 2016-12701) was obtained before starting the study.

\subsection{Data Analysis}

Descriptive analyses were done to provide information about the general characteristics of the data. Data of continuous variables were expressed as mean \pm standard deviation values, while categorical variables were presented as $\mathrm{n}(\%)$. The comparison of the means of the quantitative variables 
between the groups was conducted using the significance of the difference between two means test and one-way analysis of variance test. A chi-square test was employed to evaluate the relationship between qualitative variables. The statistical significance was accepted as $p<0.05$. Analyzes were performed on the SPSS statistical software package (IBM SPSS Statistics 19, SPSS Inc., An IBM Co., Somers, NY).

\subsection{Limitations of the study}

We were able to only evaluate the knowledge aspect of the training provided, but the application part could not be evaluated. With the provision of necessary conditions, the evaluation of the application in the hospital environment during the actual delivery process for each staff was planned as the second step of the study. Despite the abundant number of topics to be addressed about emergencies in and approaches to delivery, we were able to handle only 8 main topics since the training program was limited to an 8-hour.

\section{RESULTS}

Table 1 can be seen in, the socio-demographic characteristics of the emergency personnel included in the study.

Table 1. The distribution of the socio-demographic characteristics of the emergency personnel

\begin{tabular}{|c|c|c|c|}
\hline \multicolumn{2}{|c|}{ Characteristics (n:232)* } & $n$ & $\%$ \\
\hline \multirow{2}{*}{ Gender } & Male & 91 & 39.2 \\
\hline & Female & 141 & 60.8 \\
\hline \multirow{4}{*}{ Professional Title } & EMT & 162 & 69.8 \\
\hline & Paramedic (AECT) & 50 & 21.6 \\
\hline & General practitioner & 9 & 3.9 \\
\hline & Other (Health officer, nurse...) & 11 & 4.7 \\
\hline \multirow{2}{*}{ Education } & Health Vocational High School & 216 & 93.1 \\
\hline & University & 16 & 6.9 \\
\hline \multirow{2}{*}{ Marital Status } & Married & 155 & 66.8 \\
\hline & Single & 77 & 33.2 \\
\hline \multirow{3}{*}{ Place of residence } & Village & 7 & 3.0 \\
\hline & County & 116 & 50.0 \\
\hline & Province & 109 & 47.0 \\
\hline \multirow{2}{*}{$\begin{array}{l}\text { Another healthcare } \\
\text { personnel in the } \\
\text { family }\end{array}$} & Yes & 98 & 42.2 \\
\hline & No & 134 & 57.8 \\
\hline \multirow{5}{*}{$\begin{array}{l}\text { Professional title } \\
\text { of the second } \\
\text { healthcare worker } \\
\text { in the family }\end{array}$} & Midwife & 11 & 11.0 \\
\hline & Nurse & 24 & 24.0 \\
\hline & Doctor & 7 & 7.0 \\
\hline & Health officer & 26 & 26.0 \\
\hline & Other & 40 & 40.0 \\
\hline
\end{tabular}

According to the distribution of the knowledge of emergency personnel on emergencies in delivery in Table 2 , of the participants, $68.5 \%$ had enough knowledge about the emergency in delivery, $81 \%$ saw a vaginal delivery beforehand, $60.6 \%$ of those who had seen a vaginal delivery before saw it during school practice as students, $49.6 \%$ actively participated in a vaginal delivery, $40 \%$ participated in a delivery in the hospital, and the active role of $63.5 \%$ in this delivery was to assist the midwife/physician who administered the delivery.

Table 2. The distribution of some of the knowledge of the emergency personnel regarding emergencies during delivery $(n=232)$

\begin{tabular}{lcc}
\hline Characteristics & $\mathbf{n}$ & $\%$ \\
\hline Having adequate knowledge of emergencies during delivery & & \\
\hline Yes & 73 & 31.5 \\
\hline No & 159 & 68.5 \\
\hline Have you observed a vaginal delivery before? & & \\
\hline Yes & 188 & 81.0 \\
\hline No & 44 & 19.0 \\
\hline Where did you see a vaginal delivery? (n=188) & & \\
\hline In the hospital practice when I was a student & 114 & 60.6 \\
\hline In the media & 11 & 5.9 \\
\hline While working in a hospital & 10 & 5.3 \\
\hline During the delivery in the ambulance & 7 & 3.7 \\
\hline In more than one places & 46 & 24.5 \\
\hline Did you actively participate in the delivery? & & \\
\hline Yes & 115 & 49.6 \\
\hline No & 117 & 50.4 \\
\hline Where did you actively participate in the delivery? (n=115) & & \\
\hline Hospital & 46 & 40.0 \\
\hline Ambulance & 45 & 39.1 \\
\hline More than one place* & 24 & 20.9 \\
\hline What was your active role in the delivery? ( $n=115)$ & & \\
\hline Managing the delivery & 42 & 36.5 \\
\hline Assisting the midwife/physician managing the delivery & 73 & 63.5 \\
\hline *Hospital, healthcare center, ambulance, home & & \\
\hline
\end{tabular}

Table 3 shows the distribution of the responses of the emergency personnel to the pretest and posttest administration of the ED knowledge test questions. The majority of the emergency personnel were found to give incorrect answers to the questions in the following topics in the pretest: care for umbilical cord prolapse (93.1\%), the application of the Pinard maneuver (86.6\%), maternal risk factors for shoulder dystocia (85.3\%), umbilical cord clamping distance $(84.5 \%)$, the application of McRobert maneuver (84.1\%), the identification of the placenta previa (84.1\%), and the rupture time of the amniotic fluid sac (80.2\%). There was a significant increase in the rate of correct responses given by the emergency personnel in the posttest, whereas there was no increase in the correct responses to the question about "knowing the use of MgSO4". Especially, the rate of correct responses given by the emergency personnel to the questions about the following topics was observed to be quite high: umbilical cord clamping distance (15.5-94\%), the application of the McRobert maneuver (15.9-80.2\%), the indication of the Turtle sign $(22.4-80.2 \%)$, the application of the Pinard maneuver (13.4-76.3\%), identification of the Placenta Previa $(15.9-74.1 \%)$ and the position taken in the shoulder dystocia (27.2 - 87.5\%). 
Table 3. The distribution of the responses of the emergency personnel to the pretest and posttest administration of the ED knowledge test questions

\begin{tabular}{|c|c|c|c|c|c|c|c|c|}
\hline \multirow[b]{4}{*}{ QUESTIONS } & \multicolumn{8}{|c|}{ ED knowledge test } \\
\hline & \multicolumn{4}{|c|}{ Pretest } & \multicolumn{4}{|c|}{ Posttest } \\
\hline & \multicolumn{2}{|c|}{ Correct } & \multicolumn{2}{|c|}{ Incorrect } & \multicolumn{2}{|c|}{ Correct } & \multicolumn{2}{|c|}{ Incorrect } \\
\hline & $\mathrm{n}$ & $\%$ & $n$ & $\%$ & $\mathrm{n}$ & $\%$ & $n$ & $\%$ \\
\hline The characteristics of vaginal delivery & 101 & 43.5 & 131 & 56.5 & 207 & 89.2 & 25 & 10.8 \\
\hline Fetus-related factors at delivery & 190 & 81.9 & 42 & 18.1 & 206 & 88.8 & 26 & 11.2 \\
\hline Signs of the onset of delivery & 174 & 75 & 58 & 25 & 224 & 96.6 & 8 & 3.4 \\
\hline Purposes of protecting the perineum in delivery & 95 & 40.9 & 137 & 59.1 & 129 & 55.6 & 103 & 44.4 \\
\hline Features of real delivery contractions & 146 & 62.9 & 86 & 37.1 & 191 & 82.3 & 41 & 17.7 \\
\hline Rupture of time of the amniotic fluid sac & 46 & 19.8 & 186 & 80.2 & 115 & 49.6 & 117 & 50.4 \\
\hline Symptoms of the separation of the placenta & 165 & 71.1 & 67 & 28.9 & 207 & 89.2 & 25 & 10.8 \\
\hline Symptoms at the stage of delivery & 138 & 59.5 & 94 & 40.5 & 149 & 64.2 & 83 & 35.8 \\
\hline Applications to puerperant with postpartum hemorrhage & 210 & 90.5 & 22 & 9.5 & 216 & 93.1 & 16 & 6.9 \\
\hline Position to be taken in case of cord prolapse & 86 & 37.1 & 146 & 62.9 & 185 & 79.7 & 47 & 20.3 \\
\hline Position to be taken in shoulder dystocia & 63 & 27.2 & 169 & 72.8 & 203 & 87.5 & 29 & 12.5 \\
\hline The application of McRobert maneuvering & 37 & 15.9 & 195 & 84.1 & 186 & 80.2 & 46 & 19.8 \\
\hline Clamping distance of the umbilical cord of the newborn & 36 & 15.5 & 196 & 84.5 & 218 & 94 & 14 & 6 \\
\hline Definition of the cord prolapse & 83 & 35.8 & 149 & 64.2 & 136 & 58.6 & 96 & 41.4 \\
\hline Emergency care principles of the cord prolapse & 77 & 33.2 & 155 & 66.8 & 147 & 63.4 & 85 & 36.6 \\
\hline Definition of Placenta Previa & 37 & 15.9 & 195 & 84.1 & 172 & 74.1 & 60 & 25.9 \\
\hline Maternal risks for shoulder dystocia & 34 & 14.7 & 198 & 85.3 & 78 & 33.6 & 154 & 66.4 \\
\hline Care for Cord Prolapse & 16 & 6.9 & 216 & 93.1 & 21 & 9.1 & 211 & 90.9 \\
\hline Management of placental anomalies & 59 & 25.4 & 173 & 74.6 & 184 & 79.3 & 48 & 20.7 \\
\hline The application of Mauriceau-Smellie-Veit maneuver & 71 & 30.6 & 161 & 69.4 & 198 & 85.3 & 34 & 14.7 \\
\hline Principles for MgSO4 use & 56 & 24.1 & 176 & 75.9 & 50 & 21.6 & 182 & 78.4 \\
\hline The indication of the Turtle sign & 52 & 22.4 & 180 & 77.6 & 186 & 80.2 & 46 & 19.8 \\
\hline Responsibilities in the care and follow-up of the placenta previa & 90 & 38.8 & 142 & 61.2 & 124 & 53.4 & 108 & 46.6 \\
\hline Getting fetal heart sounds in breech presentation & 63 & 27.2 & 169 & 72.8 & 159 & 68.5 & 73 & 31.5 \\
\hline The application of the Pinard maneuvering & 31 & 13.4 & 201 & 86.6 & 177 & 76.3 & 55 & 23.7 \\
\hline
\end{tabular}

Table 4 shows the comparison of the mean scores of the emergency personnel regarding the pretest and posttest administration of the ED knowledge test. The mean of the total score obtained from the pretest was $37.17 \pm 10.36$, and the mean of the total score obtained from the posttest was $70.14 \pm 11.33$. The difference between the two was found statistically significant $(p<0.001)$.

Table 4. The comparison of the mean scores of the emergency personnel obtained from the pretest and posttest administration of the ED knowledge test

\begin{tabular}{|c|c|c|c|c|c|}
\hline ED Knowledge Test & Mean \pm SD & Min. & Max. & $\mathbf{t}$ & p \\
\hline $\begin{array}{l}\text { Mean Pretest Total } \\
\text { Score }\end{array}$ & $37.17 \pm 10.36$ & 12.00 & 76.00 & \multirow{2}{*}{40.858} & \multirow{2}{*}{$<0.001$} \\
\hline $\begin{array}{l}\text { Mean Posttest Total } \\
\text { Score }\end{array}$ & $70.14 \pm 11.33$ & 36.00 & 96.00 & & \\
\hline
\end{tabular}

As shown in Table 5, in the comparison of the mean pretestposttest and total scores of the emergency personnel obtained from the ED Knowledge test with socio-demographic features, the intra-group comparisons of all variables were determined to be statistically significant $(<0.001)$. In the inter-group comparison of the variables, the mean of the pretest, posttest, and total scores for gender, profession, and educational status were found to be statistically significant $(p<0.05)$.

As shown in Table 6, in the comparison of the mean pretestposttest and total scores of the emergency personnel obtained from the ED Knowledge test with some properties related to the emergencies in delivery, the intra-group comparisons of all variables were determined to be statistically significant $(<0.001)$. In the inter-group comparisons, a significant difference was found between "the status of actively participating in vaginal delivery" and the pretest-posttest scores and means of the total scores, and between "the place of active participation" and the posttest score and means of total scores $(p<0.001)$ 
Table 5. The comparison of the mean pretest-posttest and total scores of the emergency personnel obtained from the ED Knowledge test with socio-demographic features

\begin{tabular}{|c|c|c|c|c|c|}
\hline \multirow[b]{3}{*}{ Variable } & \multicolumn{4}{|c|}{ ED Knowledge Test } & \multirow[b]{3}{*}{$p_{1}$} \\
\hline & \multirow[b]{2}{*}{$\mathrm{n}$} & Pretest & Posttest & Total & \\
\hline & & Mean \pm SD & Mean \pm SD & Mean \pm SD & \\
\hline \multicolumn{6}{|l|}{ Gender } \\
\hline Female & 91 & $34.64 \pm 9.86$ & $67.03 \pm 11.06$ & $50.84 \pm 0.91$ & $<0.001$ \\
\hline Male & 141 & $38.81 \pm 10.38$ & $72.14 \pm 11.08$ & $55.48 \pm 0.73$ & $<0.001$ \\
\hline$p_{2}$ & & $<0.001$ & 0.011 & $<0.001$ & \\
\hline \multicolumn{6}{|l|}{ Marital status } \\
\hline Married & 155 & $37.26 \pm 10.04$ & $70.09 \pm 11.21$ & $53.68 \pm 8.61$ & $<0.001$ \\
\hline Single & 77 & $36.99 \pm 11.05$ & $70.23 \pm 11.65$ & $53.61 \pm 9.65$ & $<0.001$ \\
\hline$p_{2}$ & & 0.848 & 0.928 & 0.957 & \\
\hline \multicolumn{6}{|l|}{ Place of residence } \\
\hline Village & 7 & $37.14 \pm 8.23$ & $68 \pm 10.07$ & $52.57 \pm 7.55$ & $<0.001$ \\
\hline County & 116 & $37.14 \pm 8.98$ & $70.07 \pm 10.91$ & $53.6 \pm 7.67$ & $<0.001$ \\
\hline Province & 109 & $37.21 \pm 11.83$ & $70.35 \pm 11.92$ & $53.78 \pm 10.27$ & $<0.001$ \\
\hline p2 & & 0.999 & 0.999 & 0.939 & \\
\hline \multicolumn{6}{|l|}{ Profession } \\
\hline EMT & 162 & $36.57 \pm 9.04^{b}$ & $69.53 \pm 10.57^{b}$ & $53.05 \pm 7.5^{b}$ & $<0.001$ \\
\hline Paramedic & 50 & $36.56 \pm 9.86^{b}$ & $70 \pm 12.32^{b}$ & $53.28 \pm 9.54^{b}$ & $<0.001$ \\
\hline Physician & 9 & $46.67 \pm 16^{a}$ & $81.33 \pm 11.49^{a}$ & $64 \pm 13.11^{\mathrm{a}}$ & $<0.001$ \\
\hline \multicolumn{6}{|l|}{ Health officer, } \\
\hline Nurse, Midwife & 11 & $41.09 \pm 19.44^{\mathrm{ab}}$ & $70.55 \pm 14.12^{\mathrm{ab}}$ & $55.82 \pm 15.89^{\mathrm{ab}}$ & $<0.001$ \\
\hline p2 & & 0.019 & 0.025 & 0.003 & \\
\hline \multicolumn{6}{|l|}{ Level of education } \\
\hline University & 16 & $43.5 \pm 11.49$ & $77.25 \pm 10.9$ & $60.38 \pm 10.15$ & $<0.001$ \\
\hline $\begin{array}{l}\text { Health vocational } \\
\text { high School }\end{array}$ & 216 & $36.7 \pm 10.15$ & $69.61 \pm 11.21$ & $53.16 \pm 8.68$ & $<0.001$ \\
\hline p2 & & 0.011 & 0.009 & 0.002 & \\
\hline
\end{tabular}

Two-way repeated measures ANOVA was used for repeated measures. $P$ : significance $(P<0.05)$. $p_{1}$ : Intra-group comparison p2: Inter-group comparison (abc: common letter refers to statistical insignificance)

Table 6. The comparison of the mean pretest-posttest and total scores of the emergency personnel obtained from the ED Knowledge test with some properties related to the emergencies in delivery

\begin{tabular}{|c|c|c|c|c|c|}
\hline \multirow{3}{*}{ Some properties related to the emergencies in delivery } & \multicolumn{4}{|c|}{ ED Knowledge Test } & \multirow[b]{3}{*}{ p. } \\
\hline & $n$ & Pretest & Posttest & Total & \\
\hline & & Mean $\pm S D$ & Mean \pm SD & Mean \pm SD & \\
\hline \multicolumn{6}{|l|}{ Knowledge of emergencies } \\
\hline \multicolumn{6}{|l|}{ during delivery } \\
\hline Yes & 73 & $37.59 \pm 10.51$ & $69.7 \pm 10.54$ & $53.64 \pm 8.86$ & $<0.001$ \\
\hline No & 159 & $36.98 \pm 10.32$ & $70.34 \pm 11.7$ & $53.66 \pm 9.02$ & $<0.001$ \\
\hline \multicolumn{6}{|l|}{ Status of active participation in a vaginal delivery } \\
\hline Yes & 113 & $38.97 \pm 9.75$ & $69.95 \pm 11.2$ & $54.46 \pm 8.46$ & $<0.001$ \\
\hline No & 119 & $35.46 \pm 10.67$ & $70.32 \pm 11.5$ & $52.89 \pm 9.37$ & $<0.001$ \\
\hline p2 & & 0.010 & 0.803 & 0.183 & \\
\hline \multicolumn{6}{|l|}{ Place of the active } \\
\hline \multicolumn{6}{|l|}{ participation } \\
\hline Ambulance & 45 & $39.47 \pm 7.8$ & $65.6 \pm 10.7^{b}$ & $52.53 \pm 7.52^{\mathrm{b}}$ & $<0.001$ \\
\hline More than one place & 24 & $35.67 \pm 13.13$ & $68.83 \pm 13.24^{\mathrm{ab}}$ & $52.25 \pm 10.8^{\mathrm{ab}}$ & $<0.001$ \\
\hline \multirow{2}{*}{\multicolumn{6}{|c|}{ A second healthcare }} \\
\hline & & & & & \\
\hline Yes & 98 & $37.88 \pm 11.3$ & $69.22 \pm 12.08$ & $53.55 \pm 9.74$ & $<0.001$ \\
\hline No & 134 & $36.66 \pm 9.63$ & $70.81 \pm 10.75$ & $53.73 \pm 8.37$ & $<0.001$ \\
\hline$\frac{\mathrm{p}_{2}}{A^{2} \text { tive rele in the delivery }}$ & & 0.377 & 0.295 & 0.880 & \\
\hline \multicolumn{6}{|l|}{$\begin{array}{l}\text { Active role in the delivery } \\
\text { Management of the delivery }\end{array}$} \\
\hline Management of the delivery & 42 & $39.33 \pm 9.35$ & $68.1 \pm 10.58$ & $53.71 \pm 8.12$ & $<0.001$ \\
\hline Assisting midwife/physician managing the delivery & 73 & $38.41 \pm 10.13$ & $70.9 \pm 11.44$ & $54.66 \pm 8.67$ & $<0.001$ \\
\hline \multicolumn{6}{|c|}{$\begin{array}{l}p_{2} \\
\text { Two-way repeated measures ANOVA was used for repeated measures. } P \text { : significance }(P<0.05) . p_{1}: \text { Intra-group comparison } p_{2}: \text { Inter-group comparison (ab } \\
\text { common letter refers to statistical insignificance) }\end{array}$} \\
\hline
\end{tabular}




\section{DISCUSSION}

This study discussed the outcomes of the training given to personnel working in emergency health service units to update their knowledge and skills about the methods of treatment and intervention in emergencies during delivery.

There is limited research abroad and in our country into the knowledge and skills of the personnel working in health services about the management of emergencies during delivery $(3,24,25,27,34,35)$. In this respect, our study is of significance as an original study. Also, we think that the scarcity of scientific studies related to this topic and the sample group in emergency health services is a limitation of the discussion. Considering that $40 \%$ of the participants who participated in an active delivery participated in a delivery in the ambulance, and also, 36.5\% of them managed the delivery actively, it will be again emphasized that emergency personnel should have knowledge and skills about the emergencies in delivery.

According to 2013 data, $2.3 \%$ of maternal deaths occurred during referrals to hospitals. Therefore, improving the referral system is one of the most important steps in reducing maternal mortality. To enhance the system, it is very important to improve the knowledge and skills of health personnel providing the service, as well as replenishing the medical equipment and infrastructure deficiencies of health institutions (9). In our study, the majority of the personnel were found to not have sufficient information about emergencies during delivery and their role was determined to be limited to assisting the midwife/physician during delivery (Table 2). These data indicated that providing this training to emergency service personnel was quite an accurate decision.

According to the findings of NMMS, factors related to healthcare providers such as incomplete diagnosis, lack of knowledge, and the inability of health personnel to cope with the problem played a role in $13.7 \%$ of maternal deaths (9). Therefore, it is important for team members to know their duties and how they will function most effectively in emergencies when an obstetric emergency is encountered. To do this, they need to be familiar with clinical conditions, diagnoses and treatments, medications, the use, administration, and side effects of medications, and emergency equipment and their functions.

When the pretest-posttest results of the personnel were examined, a significant increase was observed in the level of knowledge (in the rate of correct responses to the questions) (Table 3).On the other hand, a decrease was determined in the rate of correct responses to the question about "knowing the use of MgSO4" with a decrease from $24.1 \%$ to $21.6 \%$. The low success rate relating to this question may have been because it was not understood or learned adequately. The rate of correct responses to the questions in the following areas was determined to increase especially in the posttest considerably: the umbilical cord clamping distance, the application of the McRobert and Pinard maneuver, the Turtle sign symptom, the identification of the Placenta Previa, and the position taken in shoulder dystocia. This result suggested that the personnel were adequately informed about these issues and that they learned these topics better. Also, the fact that questions with high correct answers were particularly related to applied areas showed the necessity and effectiveness of simulation application in education. Findings of the rate of simulation-based training were also observed to be high in studies in the literature, which supported the findings of our study. Walker et al. (2014) determined that there was an increase in team performance and self-efficacy levels of midwives and obstetricians who participated in simulation-based training. Calvert et al. (2013) found that the team participating in the simulation training was more successful in intervening in the eclampsia crisis. Draycott et al. (2000) determined that the rate of injuries in the baby due to shoulder dystocia decreased from $9.3 \%$ to $2.3 \%$ after simulation-based training. Besides, Merien et al. (2010) found that midwives and obstetricians who completed the simulation training carried out the delivery within 5 minutes in cases of shoulder dystocia delivery. Dayal et al. (2009) performed a study with medical students and reported that in the experimental group in which the simulation method was applied, the performance of the students in vaginal birth maneuvers, their participation in clinical applications and their self-confidence were higher than the control group.

Obstetric emergencies are special situations that can affect both the health of the mother and the fetus at the same time, requiring team collaboration and highlighting fast and correct intervention (36). In the present study, when the means of the total scores of the emergency personnel obtained from the pretest and posttest administration of the ED Knowledge test were compared, a significant increase was observed in the posttest mean scores and the difference was statistically significant ( $p<0.001$, Table 4$)$. This result showed that the training provided significantly increased the knowledge of the personnel regarding emergencies in and approaches to delivery, and the effectiveness of the training was good. The reason for success can be attributed to the following aspects: the willingness of the personnel for simulation training, the expertise of the trainers in their subjects, the presentations which were prepared using visual content, the use of simulation with active learning methods, and the increase in its effectiveness. The results of the basic module training given to personnel by Çalışkan et al. (2016), Ülger et al. (2013), and Söğüt et al. (2008) were found to be significant and similar to those of our study in terms of the comparison of mean pretest-posttest total scores $(3,11)$. Training conducted using medium level simulation has a higher benefit than training conducted using lowlevel simulation. In a systematic review by ildan Çalım and Öztürk (2018), the simulation-based training about before, while, and after delivery care given to midwifery students proved effective in ensuring readiness for the clinical setting. As for our study, we can say that the training conducted with medium level simulation significantly increased the knowledge of the personnel and that it was effective. Apart from this, the low or high fidelity sensitivity of the simulation 
model may affect the outcome of the training. In a study with 45 doctors and 35 midwives, the shoulder dystocia training provided by a high fidelity simulation method was found to be more successful than training with low fidelity simulation in delivery (39). Although the delivery simulation model used in our study was a medium sensitive simulator, it could be said to have an important contribution to increasing the success in the practical part of the training.

When the pretest and posttest scores and mean total scores of the emergency personnel were compared with their sociodemographic characteristics, the intra-group comparisons of all variables were found to be statistically highly significant $(<0.001)$. In the inter-group comparison of the variables, the relationship between the mean pretest and posttest total scores and gender, occupation, and education level was determined to be statistically significant $(p<0.05$, Table 5). Unlike our study, the study of Ülger et al. (2013) found no difference between professions in terms of the pretest and posttest scores in the training they gave to ambulance personnel. In a study with physicians group, Kavalci et al. (2009) and Eryilmaz et al. (2007) attributed the high scores obtained from the training to the fact that the trainees were able to easily grasp the subjects because they were physicians, they had practical experience related to the subject, and that they had knowledge about the training content. In our study, the high success rates in the physician group can be attributed to similar reasons compared to other occupational groups.

In our study, university graduates created a difference in all mean scores compared to health vocational high school graduates. This indicated that the high level of education was important in terms of contributing positively to the effectiveness of the basic professional knowledge of individuals, and the positive increase in learning and understanding of the information provided in the current course.

When the pretest and posttest scores and mean total scores of the emergency personnel were compared with their findings regarding emergencies during delivery, intra-group comparisons of all variables were found to be statistically highly significant $(p<0.001)$. The inter-group comparisons, on the other hand, indicated that there was a statistically significant difference between the status of "active participation in a vaginal delivery" and the pretest, posttest scores and means of total scores and between the "place of the active participation" and the posttest score and means of total scores ( $p<0.05$, Table 6 ). The posttest scores of the participants who did not actively participate in a vaginal delivery were higher than those who did not. Also, the posttest scores of the participants who observed the delivery during internship had higher scores. In the study conducted with paramedic students by Tuygar (2016), 85.2\% of the students were found to think that the healthcare workers working at the places they did their internship helped them gain professional experience.

In a study conducted by Göllüce et al. (2017) with paramedic students, $31.7 \%$ of the students stated that they needed to update their knowledge and skills to specialize in their job. The findings of Göllüce et al. (2017) and the findings of this study pointed out the necessity of the training given.

\section{CONCLUSION}

In conclusion, the findings laid out that the training given increased the knowledge of the emergency health service personnel about emergencies and approaches during delivery and that it was effective. In light of the findings, we recommend that future studies should measure and evaluate the applied skills development dimension of this training, as well as assessing the pretest-posttest scores; this type of training events should be repeated periodically for healthcare personnel working in emergency health service units; both theoretical and practical course content topics such as normal delivery, obstetric emergencies, and approaches to these areas should be added to the undergraduate educational syllabus of the personnel working in emergency health service units; larger sample sizes should be used to assess the efficiency of this type of training; and that the effect of these findings on the health indicators of the region where the study is conducted should be reported.

\section{REFERENCES}

[1] T.R. Ministry of Health, General Directorate of AÇSAP. Management guide for Emergency Obstetric Care, Ankara. 2009.

[2] Soysal S, Karcıoğlu Ö, Topaçoğlu H. Emergency medical, prehospital care. Cerrahpaşa J Med. 2003;34: 51-57.

[3] Ülger H, Deniz T, Saygun M, Çiftçi N, Karakuş A, Kandiş H. Evaluation of the effectiveness of the training given to ambulance personnel. TAF Preventive Medicine Bulletin 2013;12(2): 151-156.

[4] Levels and Trends in Child Mortality. UNICEF Report 2019. https://www.unicef.org/media/60561/file/UN-IGME-childmortality-report-2019.pdf

[5] Gabrysch S, Campbell OMR. Still too far to walk: Literature review of the determinants of delivery services use. BMC Pregnancy

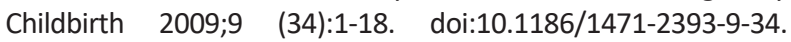

[6] Artıran İğde FA, Gül R, Yalçın M, Karadenizli D. Maternal deaths and emergency obstetric care, General Medical Journal 2008; 18: 47-53.

[7] Paxton A, Maine D, Freedman D, Fry D, Lobis S. The evidence for emergency obstetric care. Internal Journal of Gynecology Obstetric 2005; 88: 181-193. doi: 10.1016/j.ijgo.2004.11.026.

[8] Maine D. Rosenfield A. The AMDD program: History, focus and structure. Internal Journal of Gynecology Obstetric 2001; 74: 99-103. Doi: https://doi.org/10.1016/S0020-7292(01)00428-3.

[9] T. R. Public Health Agency of Turkey Ministry of Health and Women's Reproductive Health Department, Midwife / Nurse Participant Book for Emergency Obstetric Care. Ankara.2015.

[10] Başaran M, Başaran A, Adıgüzel $O$, Başaran A, Küçükaydın Z. Developing high performance organizations in obstetric emergency management of Konya province: creating a sustainable model. International Journal of Social Research 2015;8: 835-851.

[11] Çalışkan C, Koçak H, Yavuz Ö. Evaluation of the basic module training given to 112 personnel of a province in 2012. Gümüşhane University Journal of Health Sciences 2016;5 (1): 50-63. 
[12] World Health Organization. Managing complications in pregnancy and childbirth: a guide for midwives and doctors. 2nd ed. ISBN 978-92-4-156549-3. 2017. http://apps.who.int/ iris/bitstream/10665/255760/1/97.

[13] Burkhardt T, Schmıdt M, Kurmanavıcıus J, Zımmermann R, Schaffer L. Evaluation of fetal anthropometric measures to predict the risk for shoulder dystocia ultrasound. Journal of Gynecology Obstetric 2014; 43:77-82.

[14] Acker DB, Sachs BP, Friedman EA. Risk factors for shoulder dystocia in the averagee weight infant. Journal of Gynecology Obstetric 1986;67:614-8. doi:10.1097/00006.250.198605000-00002.

[15] Sukgen G, Turkay U. Uncertainted cases during vaginal birth: Shoulder dystocia. Bozok Medical of Jornal 2020;10(4):7-14. DOI: 10.16919/bozoktip.677029

[16] İngeç M, Kumtepe Y, Börekçi B, Bebek Z, Kadanalı S. Maternal and perinatal outcomes of 81 cases of eclampsia in 20012003. Journal of Gynecology Obstetric 2005;19(3): 135-141.

[17] Queenan JT, Spong CY, Lockwood CJ.( eds.) Queenan's Management of High Risk Pregnancy: An Evidence-Based Approach. 6th ed. UK: Wiley-Blackwell; 2012.

[18] Su CW. Postpartum hemorrhage. Prim Care Clinical Office Practice 2012;39(2012): 167-187.

[19] World Health Organization (WHO). Management of Complications in Pregnancy and Delivery: A Guide for Midwives and Doctors. Reproductive Health and Research Department, Family and Community Health, World Health Organization, Geneva, 1st edit. 2003. https://sbu.saglik.gov.tr/ Ekutuphane/kitaplar/Gebelik\%20\%20ve\%20\%20Do\%C4\%9Fu mda\%20Komplikasyonlar\%C4\%B1n\%20Y\%C3\%B6netimi.pdf

[20] Berry NS. Kaqchikel midwives, home births, and emergency obstetric referrals in Guatemala: Contextualizing the choice to stay at home. Social Science and Medicine, 2006;62:19581969. https://doi.org/10.1016/j.socscimed.2005.09.005

[21] WHO. Monitoring Emergency Obstetric Care, World Health Organization, Geneva. 2009

[22] T. R. Ministry of Health. Notification on the Application Procedures and Principles of Emergency Services in Inpatient Health Services. Official Gazette, Issue: 27378. Date: October 16, 2009.

[23] Taşkın L. Follow-up and care in labor. In: Taşkın L. (Ed). Maternity and Women's Health Nursing. Ankara: Reaksiyon Printing, Academician Medical Bookstore; 2016; pp. 342-536. (Turkish).

[24] Hacker N, Gambone J, Hobel C. Hacker and Moore's Essentials of Obstetrics and Gynecology. 6th Edition. Philadephia: Elsevier; 2016; pp.116-285.

[25] Hughes C, Anderson G, Patterson D, O'Prey M. Introducing an obstetric emergency training strategy into a simulated environment. British Journal of Midwifery 2014;22(3): 201-207.

[26] Shaw Battista J, Belew C, Anderson D, van Schaik S. Successes and challenges of interprofessional physiologic birth and obstetric emergency simulations in a nurse-midwifery education program. Journal of Midwifery and Women's Health 2015; 60(6), 735-743.

[27] Çam MO, Arabacı L. Qualitative and Quantitative Steps in Preparing an Attitude Scale. Turkish Journal of Research and Development in Nursing 2010;12 (2): 1-9.
[28] Aksoy F, Ergün A. The place of the ambulance in emergency health services. National Journal of Trauma 2002; (8):160-163.

[29] Calvert KL, Mcgurgan PM, Debenham E, Gratwick FJ, Maouris P. Emergency obstetric simulation training: How do we know where we are going, if we don't know where we have been?. Australian and New Zealand Journal of Obstetrics and Gynaecology 2013;53:509-516. https://doi.org/10.1111/ajo.12120

[30] Eryılmaz M, Çavuş T, Kurtipek A, Doğrucan C, Durusu M, Güleç MA, et al. Ankara Basic Life Support Module within the Scope of the Ministry of Health Emergency Medicine Certification Program: One-Year Outcome and Efficiency Evaluation. Turkey Journal of Medical Sciences 2007;27: 744-752.

[31] Kavalcı C, Güzel A, Çevik Y, Durukan P. Edirne basic education module: outcomes and efficiency evaluation of three years. Academic Emergency Medical Journal 2009;8 (3): 29-32.

[32] Merien AER, Van de Ven J, Mol BW, Houterman S. Multidisciplinary team training in a simulation setting for acute obstetric emergencies. Obstetrics and Gynecology 2010;115 (5):1021-1025. doi: 10.1097/AOG.0b013e3181d9f4cd.

[33] Walker D, Cohen S, Fritz J, Olvela M, Figueroa H, Cowan J, et al. Team training in obstetric and neonatal emergencies using highly realistic simulation in Mexico: impact on process indicators. BMC Pregnancy and Childbirth 2014;14(367):1-11. doi: 10.1186/s12884.014.0367-1.

[34] Draycott T, Broad G, Chidley K. The development of an eclampsia box and fire drill. British Journal of Midwifery 2000;8(1): 26 30. doi: https://doi.org/10.12968/bjom.2000.8.1.8195.

[35] Dayal AK, Fisher N, Magrane D, Goffman D, Bernstein PS, Katz NT. Simulation training improves medical students' learning experiences when performing real vaginal deliveries. Simulation in Healthcare 2009;4(3):155-159.

[36] Prasad D, Nishat H, Tiwary B, Nisha S, Sinha A, Goel N. Review of obstetrical emergencies and fetal out come in a tertiary care centre. International Journal of Research in Medical Sciences 2018;6(5):1554-1558. http://dx.doi.org/10.18203/23206012.ijrms20181467.

[37] Söğüt Ö, Kamaz A, Kose R, Güven G. Evaluation of the success levels after the 4 basic modules training practitioner course for the assistant health personnel in Kahramanmaraş and the affecting factors. 1st Eurasian Congress on Emergency Medicine 2008; 5-9, S-012, 49 pp, Antalya, Turkey.

[38] İldan Çalım S, Öztürk E. Simulation use in midwifery skill training: A Systematic Review, JACSD 2018;12:143-168. doi:10.17367/JACSD.2018.1.3

[39] Crofts JF, Bartlett C, Ellis D, Hunt LP, Fox R, Draycott TJ. Training for shoulder dystocia: a trial of simulation using low-fidelity and high-fidelity mannequins. Obstetrics and Gynecology 2006;108 (6):1477-1485.

[40] Tuygar ŞF. Examination of the views of the students of the Paramedic program about their summer internship. Düzce University, Journal of Health Sciences Institute 2016;6(2): 92-100.

[41] Göllüce A, Avan H, Karsu F. The paramedic profession through the eyes of the student. Pre-Hospital Journal 2017;2 (1):1-9.

How to cite this article: Yilar Erkek Z, Alparslan O, Ozturk Altinayak S. The Effect of Simulation-Based Training About Emergencies in and Approaches to Delivery Given to Emergency Personnel. Clin Exp Health Sci 2021; 11: 96-104. DOI: 10.33808/clinexphealthsci.770975 